\title{
Developing communication skills in medicine
}

\section{Asking relatives for permission for a post mortem examination}

\author{
Simon J Sherwood, Roger D Start
}

\begin{abstract}
Summary
This article discusses the possible aims, benefits, and also the content, format and timing of training in one specific aspect of clinical practice; how to request permission for post mortems.
\end{abstract}

Keywords: communication skills, education, post mortems

Department of Pathology, University of Sheffield Medical School, Beech Hill Road, Sheffield, S10 2UL, UK SJ Sherwood

RD Start

Correspondence to RD Start

Accepted 19 January 1995
There is increasing concern regarding the current world-wide decline in clinical or hospital post mortem rates. ${ }^{1}$ The reason for this concern is that the post mortem is still of benefit to both medical practice and to society. The decline is believed to be due to a number of complex factors. ${ }^{1}$ Clinicians, particularly junior clinicians, are usually responsible for approaching relatives for their permission ${ }^{2}$ although in some cases specially trained decedent affairs staff may undertake this task. ${ }^{3}$ These individuals therefore have a key role in determining hospital post mortem rates. This is particularly true in those countries which are now changing from a system whereby patients or relatives had to opt out of clinical post mortems to a system in which relatives' consent must be obtained.

A major factor in the decline in hospital post mortem rates is that fewer requests are being made. ${ }^{4}$ This may be due to a number of reasons including a fear of confronting the relatives, ${ }^{1}$ personal discomfort, ${ }^{5,6}$ an inability to explain adequately the value of the post mortem, ${ }^{7}$ a belief that relatives are becoming more reluctant to give permission, ${ }^{8}$ or a desire not to upset the relatives. ${ }^{6,9}$

The outcome of an autopsy request is highly dependent on the manner in which it is made. ${ }^{10}$ Thus, the process would be easier for all concerned if those involved in making the requests had received appropriate training and if the requesting procedures were well-established. ${ }^{3}$

\section{Training in requesting permission for a hospital post mortem}

A large number of clinicians appear to have never received any formal training or advice in how to approach relatives for permission for a post mortem..$^{2,5,11,12}$ Most clinicians learn through personal experience or by accompanying senior colleagues who have had no training themselves. ${ }^{5,12}$ Initial experiences could have long-term effects on clinicians' motivation and expectations regarding future requests, particularly if these experiences are negative. This is one reason why preparation via the provision of relevant training is important.

Many junior clinicians feel that there is a need for training in how to request post mortems. ${ }^{8,11}$ Support for this proposal has come from a wide range of clinical and non-clinical sources. ${ }^{4,7,9,13}$ It has been suggested that most basic skills required for medical practice should be acquired during the pre-registration year when supervisors have a responsibility to ensure that adequate training is provided. ${ }^{14}$

\section{Content of training}

The content and format of communication skills training should ideally be based upon a thorough assessment of training needs and the defined aims and objectives of the training programme. ${ }^{15}$ Those requiring training might include medical students, clinicians, and/or relative support staff. The General Medical Council recommends that 'Doctors must be good listeners ... and they must be able to provide advice and explanations that are comprehensible. ${ }^{14}$ More specifically, one of the objectives of the training programme might be to enable the appropriate individuals to request permission for hospital post mortems in a sensitive and understanding manner which allows the relatives to make informed decisions and minimises the risk of causing additional distress. Certain knowledge, skills and abilities might be relevant to training designed to reach this objective.

Individuals should be able to anticipate and cope with the reactions and concerns of relatives at the time of a bereavement. They should also be aware of possible religious and cultural sensitivities relating to death, funeral arrangements, and post mortem examinations. ${ }^{7,9,16}$ An appreciation of the administrative procedures, and the roles and responsibilities of those involved with the death of a patient in hospital is also important. Agencies within the hospital include clinicians, and nursing, relative support, administrative and 


\section{Deaths reportable to the coroner}

A death should be referred to the coroner if the medical practitioner cannot readily certify death as being due to natural causes within the terms of regulation 51 of the Registration of Births, Deaths and Marriages Regulations 1968. Some of the circumstances in which a death might be reported include those in which:

- there are any suspicious

circumstances or a history of violence

- the death may be linked to an accident (whenever it occurred)

- the deceased was receiving a war pension or industrial disability pension (unless the death can be shown to be wholly unconnected)

- the death may be due to industrial disease or may be related in any way to the deceased's employment

- the death is linked with an abortion

- the death occurred during an operation, or before full recovery from the effects of anaesthesia, or was in any way related to the anaesthesia

- the death may be related to a medical procedure or treatment

- the death may be due to a lack of medical care

- allegations of medical mismanagement have been made

- the actions of the deceased may have contributed to his or her own death

- the death occurred during or shortly after detention in police or prison custody

- the deceased was not seen by a doctor within the 14 days prior to death

(adapted from an article by Start $e t a l^{1}$ )

Box 1 mortuary staff together with the pathologists. Agencies outside the hospital include the coroner's office (or equivalent authority), the office of the registrar of births, deaths and marriages, funeral directors, as well as the relatives of the deceased. There should also be an appreciation of the role of other agencies such as pastoral support, voluntary and charitable organisations.

Before making a post mortem request, clinicians must recognise the circumstances in which they should report a patient death (see box 1) to the coroner (or equivalent authority). ${ }^{17}$ In some cases the circumstances in which a death should be reported may be desired local practice rather than statutory requirements. It is important that clinicans who go to work in other countries familiarise themselves with the local guidelines - for example, in the US the circumstances may vary from state to state. ${ }^{18}$ Individuals should also be able to explain the difference between medico-legal and hospital post mortems and the circumstances in which they are carried out. It seems that many of the public are unaware of this difference and a request might cause anxiety because of a belief that the cause of death is not known or that there are suspicious circumstances surrounding the death of their relative.

Clinicians should also be able to explain the cause of death using terminology which will be easily understood by the relatives. An understanding of relatives' misconceptions regarding post mortem examinations and the reasons why relatives refuse/give permission is a necessary basis for making effective requests and may alleviate possible fears and anxieties on the part of the relatives (see case history boxes $2-4) .{ }^{13}$ The most frequent reasons given by relatives for refusing permission for a post mortem are given in box 5.,16,19,20 Although clinicians are probably aware of most of these reasons, the influence of a lack of understanding of the need for a post mortem and fears over interference with funeral arrangements may not be fully appreciated.

In making a request the individual responsible should be able to explain the specific reasons why requests are made, and the benefits and continuing importance that post mortems can have for the medical profession, relatives, and for society. ${ }^{7,9,11,21}$ Medical students are often not informed of the value and utility of the post mortem examination and this will clearly influence their subsequent perceptions of its value. ${ }^{1,5}$ Although some clinicians still appear to recognise the importance of post mortems, there is evidence to suggest that they are not aware of the full extent and nature of the information that they can provide (see boxes $6-8) .{ }^{11}$

The request should be made in a manner that does not put pressure on relatives, who should be given time to consider and discuss their decision if they so wish. The clinician should have an understanding of the nature of post mortems and the possible alternatives to a full examination (eg, limited post mortem or a needle core biopsy) together with the practicalities involved with the arrangement of the examination and the dissemination of the results. This would enable them to deal with any questions raised by relatives.

A suitable training programme must promote the necessary knowledge, skills, and abilities as well as a positive attitude towards the issue of requests for post mortems. For example, clinicians should be encouraged to take responsibility for ensuring that relatives who give consent, receive the results of the examination as soon as possible.

Ideally, formal training in requesting permission for post mortems should be part of a comprehensive programme designed to provide a range of communication skills appropriate to dealing with death and dying.,22 There appears to be growing acceptance of the need for formal communication skills training within this type of educational context which is directly relevant to clinical practice. ${ }^{23,24}$

\section{Benefits of training in how to request permission for a hospital post mortem}

The provision of relevant training could increase clinicians' motivation to request a post mortem by increasing their perceptions of its value and by increasing their confidence in their ability to approach relatives. Such training might also make them feel more comfortable with the task and increase their expectations of gaining permission. ${ }^{25}$ Improvements in the quality of the requests made could lead to increases in hospital post mortem rates due to greater success rates in gaining permission. ${ }^{26}$ Improvements could also reduce the likelihood of causing additional distress to relatives, which is an obvious concern of clinicians, and could lead to a better and more accurate understanding of the nature and importance of the post mortem by the general public. 


\section{Case history of a relative's concerns}

Possible mutilation and disfigurement

A son is concerned that a post mortem examination would result in his mother's body being cut up and practised upon by medical students leading to disfigurement. In particular, he does not like the idea of any interference with her head as he wishes to have an open casket at the funeral service.

\section{Reassurances}

- the post mortem examination is similar to a surgical operation and is carried out by medically qualified pathologists

- the outward appearance of the deceased would not be altered in any way and no external marks would be visible

- if preferred, the next of kin could opt for a limited post mortem examination (which could specify avoidance of the head) or a needle core biopsy. (These options are only available in non-medicolegal cases where consent is required from the next of kin.)

\section{How is communication skills training being provided?}

The most commonly used teaching methods for communication skills training in the UK medical schools are tutorials, video feedback, role-playing and lectures. ${ }^{23,27}$ Self-teaching workshops, and group discussion appear to be less frequently used. It is difficult to draw conclusions about the relative frequency of the use of real and simulated patients because of differences in the level of data collected in these surveys. Teaching methods are clearly an important issue since the effectiveness of training will be dependent on these methods as well as on the complexity of the required skills. ${ }^{28}$ There are currently insufficient data to assess the relative effectiveness of different teaching methods. ${ }^{23}$

Clinicians appear to prefer more active teaching techniques such as small group seminars and tutorials, group discussion, and the use of demonstration videos, video feedback sessions and role-play. More passive teaching methods including written guidelines and lectures are considered to be less desirable. ${ }^{5}$ Most UK medical schools seem to be striving to move away from lectures towards more small-group learning. ${ }^{14}$

\section{When is communication skills training provided?}

More than a third of all communication skills training in British medical schools ${ }^{23}$ appears to be provided during the first clinical year. There is growing support for the introduction of integrated communication skills training which would begin in the undergraduate curriculum and continue into postgraduate and continuing medical education. ${ }^{23,24,29}$ Other suggestions have been that it would be difficult to provide training at the undergraduate level and that this might best be provided at the beginning of the pre-registration year. ${ }^{14,30}$ Some clinicians consider the most desirable time for such training to be between the beginning of the final undergraduate year and the end of the pre-registration year. ${ }^{5}$

The ideal communication skills training programme may be one which provides training at appropriate times during the undergraduate medical education (for example, post mortem requests could be introduced during the teaching of pathology) and then reinforces key skills of direct relevance to specific areas of clinical practice in the pre-registration year, in postgraduate and in continuing medical education.

\section{Case history of a relative's concerns}

\section{Lack of understanding of the} justification for a post mortem examination

A sister does not understand what possible benefits could be gained from a post mortem examination if the cause of her elderly brother's death is already known.

\section{Reassurances}

- the post mortem may provide useful information which was not available when the patient was alive

- post mortem examinations can be beneficial, not just to the medical profession, but also to the relatives and society in general, eg, through the demonstration of hereditary or infectious diseases

- the medical profession can gain vital feedback concerning the accuracy of clinical diagnosis and effects of treatment

- the results may assist relatives with the grieving process. It may be a comfort to know more about the cause of death and that all appropriate care was given.

\section{Reasons for refusal of a} post mortem

- concerns about disfigurement and further suffering

- perceived stress of giving permission

- objections from other family members

- the wishes of the deceased

- lack of information concerning the reasons for the post mortem

- religious/cultural objections (eg, from Jews, Muslims, Christian Scientists, Zoroastrians, the Afro-Caribbean community and Rastafarians)

- concern over possible interference with funeral arrangements

- a desire to conclude matters as soon as possible

Box 5 


\section{The benefits of the post mortem}

For the medical profession

- establishes a precise cause of death

- improves the accuracy of epidemiological statistics clinical diagnoses

- gives information on the effects of (new) drugs, treatments, surgical procedures, and disease processes

- aids undergraduate/postgraduate medical education

- aids medical audit and risk management

Box 6
- gives feedback on the accuracy of

\section{The benefits of the post} mortem

\section{For the relatives}

- knowledge of precise cause of death

- alleviation of guilt through reassurance that death was inevitable and that all appropriate care was given

- assistance in the advancement of medical knowledge

- an opportunity to help others

- assistance with the grieving process

- identification of possible hereditary conditions and diseases and infectious diseases

- assistance with insurance and compensation claims

Box 7

1 Hill RB, Anderson RE. The autopsy - medical practice and public policy. Boston: Butterworths,

2 Chana J, Rhys-Maitland R, Hon P, Scott P, Thomas C, Hopkins A. Who asks permission for an autopsy? $\mathcal{F} R$ Coll Physicians Lond 1990; 24: 185-8.

3 Haque AK, Cowan WT, Smith JH. The decedent affairs office: a unique centralized service. fAMA 1991; 266: 1397-9.

4 McPhee SJ, Bottles K, Lo B, Saika G, Crommie $D$. To redeem them from death: reactions of family members to autopsy. $A m \mathcal{F}$ Med $1986 ; 80$ : 665-71.

5 Sherwood SJ. Motivation to request permission for hospital autopsies: the predictive utility of clinicians' strength of self-efficacy, outcome clinicians' strength of self-efficacy, outcome
expectations, and outcome values. MSc Dissertation. Sheffield, England: University of tation. Sheffield,

6 Birdi KS. A comparison of the theory of planned behaviour and the theory of reasoned action in the context of requesting hospital autopsies. (MSc dissertation). Sheffield, England: University of Sheffield, 1992.

7 Charlton R. Autopsy and medical education: a review. $\mathscr{F} R$ Soc Med 1994; 87: 232-6.

8 Wilkes MS, Link RN, Jacobs TA, Fortin AH, Felix JC. Attitudes of house officers toward the autopsy. F Gen Intern Med 1990; 5: 122-5.

9 Report of the Joint Working Party of the Royal College of Pathologists, the Royal College of Physicians of London and the Royal College of Surgeons of England. The autopsy and audit. London: Royal College of Pathologists, 1991.
$10 \mathrm{McGoogan} \mathrm{E}$. The autopsy and clinical diagnosis. FR Coll Physicians Lond 1984; 18: 240-3

11 Hinchliffe SA, Godfrey HW, Hind CRK Attitudes of junior staff to requesting permissio for autopsy. Postgrad Med $\mathcal{f}$ 1994; 70: 292-4.

12 Katz JL, Gardner R. The intern's dilemma: the request for autopsy consent. Psychiatry Med

13 Brown HG. Perceptions of the autopsy: views from the lay public and program proposals. Hum Pathol 1990; 21: 154-8.

14 The General Medical Council Education Committee. Tomorrow's doctors: recommendations on mitter. Tomatrow's doctors: recommendations on undergraduate medical education.

15 Patrick J. Training research and practice. Patrick J. Training research

16 London: Academic Press, 1992. Green J, Green M. Dealing with death: practices and procedures. London: Chapman Hall, 1992.

7 Start RD, Delargy-Aziz Y, Dorries CP, Silcocks PB, Cotton DWK. Clinicians and the coronial system: ability of clinicians to recognise reportable deaths. $B M \mathcal{F}$ 1993; 306: 1038-41.

18 Schmidt S. Consent for autopsies. FAMA 1983; 250: 1161-4.

19 Geller SA. Religious attitudes and the autopsy. Arch Pathol Lab Med 1984; 108: 494-6.

20 Gatrad AR. Mulsin customs surrounding death bereavement, postmortem examinations, and organ transplants. $B M \mathcal{F} 1994 ; 309: 521-3$.

21 Start RD, Hector-Taylor MJ, Cotton DWK Startup M, Parsons MA, Kennedy A. Factors which influence necropsy requests: a psychological approach. f Clin Pathol 1992; 45: psychol. 1972; 3: 197-203.
The benefits of the post mortem

For society in general

- improved accuracy of epidemiological statistics

- organ and tissue donation

- identification and monitoring of occupational and environmental health hazards

- identification and monitoring of infectious diseases and epidemics - increase in medical knowledge

Box 8

22 Field D. Formal instruction in United Kingdom medical schools about death and dying. Med Educ 1984; 18: 429-34.

23 Whitehouse CR. The teaching of communication skills in United Kingdom medical schools. Med Educ 1991; 25: 311-8.

24 Consensus statement from the Workshop on the Teaching and Assessment of Communication Skills in Canadian Medical Schools. Can Med Assoc f 1992; 147: 1149-50.

25 Cottreau C, McIntyre I, Favara BE. Professional attitudes toward the autopsy: a survey of clinicians and pathologists. Am $\mathcal{F}$ Clin Pathol 1989, 92: 673-6.

26 Clayton SA, Sivak SL. Improving the autopsy rate at a university hospital. Am $\mathcal{F}$ Med 1992;92. rate at a

27 Frederikson L, Bull P. An appraisal of the current status of communication skills trainin in British medical schools. Soc Sci Med 1992; 34 515-22.

28 Maguire P. Can communication skills be taught? Br ₹ Hosp Med 1990; 43: 215-6.

29 Heavey A. Learning to talk with patients. $\mathrm{Br} F$ Hosp Med 1988; 39: 433-9.

30 Jolly BC, MacDonald MM. Education for practice: the role of practical experience in undergraduate and general clinical training. Med Educ 1989; 23: 189-95.

\section{Developing communication skills in medicine}

\section{Forthcoming articles in this series}

Telling a patient he/she has multiple sclerosis

Counselling junior medical staff

Telling parents their child has severe congenital anomalies

Counselling a patient for an HIV test 